\title{
Pricing of the Quanto Game Option with Asian Feature
}

\author{
Guo Peidong \\ School of Management, Shanghai University of Engineering Science, Shanghai, China
}

\section{Email address:}

gpeidong@yeah.net

\section{To cite this article:}

Guo Peidong. Pricing of the Quanto Game Option with Asian Feature. Journal of Finance and Accounting. Vol. 8, No. 3, 2020 , pp. $143-147$. doi: $10.11648 /$ j.jfa.20200803.15

Received: April 20, 2020; Accepted: June 7, 2020; Published: June 8, 2020

\begin{abstract}
The game option, which is also known as Israel option, is a new type of American option to give the option writer the right to cancel the contract before the maturity. This article studies the pricing behaviors of the quanto game option with Asian features based on partial differential equation and the stochastic analysis. The Asian feature in an option model refers to the payoff of the option depends on both the average asset price over the life of the option. The quanto options (currency-translated foreign equity options) are contingent claims where the payoff depends on exchange rate level at the option exercise time. The Asian quanto game options can be regarded as double-barrier European options for the features that both the holder and the writer can exercises the options contract at any time over the life of the option. We derive the pricing equation and provide the integral expression of pricing formula for the option. The option price is decomposed into the corresponding European option price and the penalty paid by the option writer for an early callable and the penalty paid by the option holder for early exercise of the option. In addition, we discuss optimal exercise strategies and continuation regions of the option.
\end{abstract}

Keywords: American Option, Quanto Game Option, Asian Feature, Callable Strategy

\section{Introduction}

The game option is an innovative American option, in which the contract seller can exercise the contract at any time over the life of the option. If the option holder exercises the contract at time $t$ before the maturity $\mathrm{T}$, he gets the payoff $\mathrm{X}_{\mathrm{t}}$. On the other hand, if the contract is cancelled by the option writer, the option writer gives the option holder payoff $Y_{t}$. If the option holder exercises the contract at the time when the writer cancels the contract, the option holder can only get the payoff $\mathrm{X}_{\mathrm{t}}=\mathrm{Y}_{\mathrm{t}}$. In the call game option case, $\mathrm{X}_{\mathrm{t}}=(\mathrm{S}-\mathrm{K})^{+}$and $\mathrm{Y}_{\mathrm{t}}=(\mathrm{S}-\mathrm{K})^{+}+\delta$, where $\delta$ denotes the penalty. There is a strong interest in this area of the American style derivatives in the recent years which is confirmed by the large amount of publications - see for example Park and Jeon (2017), Le and Dang (2017), Balajewicz and Toivanen (2017), Gong and Zhuang (2017), Kang et al. (2017), Zhao and Yang (2018), Chen et al. (2018), Madi et al. (2018), Soleymani et al. (2018), Chen et al. (2019), Zaevski (2019) and Gao et al. (2020).

Following the arguments by Kifer (2000) and Kyprianou (2004) we know that the optimal strategy for the writer is to stop only when $\mathrm{S}_{\mathrm{t}}=\mathrm{K}$. Similarly to the case of the American option, the goal of the game option holder is to maximize his payoff. The game option writer, however, has to hedge his short position and at the same time, when he cancels the contract, minimizes the payoff obtained by the option holder. In some sense, the game option can be viewed as an American option that the writer has the right to cancel the contract before the maturity. Since the writer could cancel the contract before the maturity, the price of the game option should not be higher than the price of the corresponding American option. The relevant conclusions of the game option pricing can be found in Kyprianou (2004), Baurdoux (2004), Ekstrom (2006), Kuhn, C., and a. e. Kyprianou. (2007), Guo Peidong (2014), Yam et al.(2014), Tsvetelin et al.(2020).

The aim of this article is to study the pricing behavior of the quanto game option with the Asian feature whose payoffs depend on the mean of the underlying asset price during the life of the option. We analyze the optimal exercise strategies and derive the pricing formula of the quanto game option with the Asian feature. The paper is organized as follows. In Sect. 2 we derive the pricing equation of the quanto game option with the Asian feature. We also study the optimal 
exercise strategies and the characteristics of continuation regions of the option. In Sect. 3 we derive the pricing formula of the quanto game option with the Asian feature with floating strike in domestic currency. The numerical simulation analysis and the conclusion are in Sect. 4.

\section{The Pricing Equation}

Under the risk neutral condition, the asset price process follows a lognormal diffusion process

$$
\begin{gathered}
\mathrm{dS}^{*}=\mu_{\mathrm{S}^{*}} \mathrm{~S}^{*} \mathrm{dt}+\sigma_{\mathrm{S}^{*}} \mathrm{~S}^{*} \mathrm{dW}_{1} \\
\mathrm{~d} S=\mu_{\mathrm{S}} \mathrm{Sdt}+\sigma_{\mathrm{S}} \mathrm{SdW}_{2} \\
\mathrm{dF}=\mu_{\mathrm{F}} \mathrm{Fdt}+\sigma_{\mathrm{F}} \mathrm{FdW}_{3}
\end{gathered}
$$

where $\mathrm{W}_{\mathrm{i}}(\mathrm{i}=1,2,3)$ denotes the standard Wiener process, and $\sigma_{\Delta}, \mu_{\Delta}\left(\Delta=\mathrm{S}^{*}, \mathrm{~S}, \mathrm{~F}\right)$ represent the drift rate and the volatility of the asset return respectively. Let $\rho_{\mathrm{SF}}$ be correlation coefficient of the standard Wiener process $\mathrm{W}_{2}$ and $\mathrm{W}_{3}$.

Further let $\mathrm{T}$ denote the expiration time of the option. Denote the divided yield, the domestic and foreign risk-free interest rate by $\mathrm{r}>0, \mathrm{r}_{\mathrm{f}}>0, q>0$, respectively. According to $\mathrm{S}^{*}=\mathrm{FS}$, we have

$$
\begin{gathered}
\mu_{S^{*}}=\mu_{\mathrm{S}}+\mu_{\mathrm{F}}+\rho_{\mathrm{SF}} \sigma_{\mathrm{S}} \sigma_{\mathrm{F}} \\
\sigma_{\mathrm{S}^{*}}^{2}=\sigma_{\mathrm{S}}^{2}+\sigma_{\mathrm{F}}^{2}+\rho_{\mathrm{SF}} \sigma_{\mathrm{S}} \sigma_{\mathrm{F}} \mathrm{SF} .
\end{gathered}
$$

Now we consider the quanto Asian game (QAG) option where the strike price is denominated in domestic currency and the strike price follows the geometric average distribution, namely

$$
\mathrm{G}_{\mathrm{S}^{*}}=\exp \left\{\frac{1}{\mathrm{t}} \int_{0}^{1} \ln \mathrm{S}^{*}(\tau) \mathrm{d} \tau\right\}, 0 \leq \mathrm{t} \leq \mathrm{T} .
$$

According to the principle of the no-arbitrage pricing and Itô lemma, the QAG option satisfies the following equation

$$
\begin{aligned}
& V_{\mathrm{t}}+\frac{1}{2} \sigma_{\mathrm{S}}^{2} \mathrm{~S}^{2} \mathrm{~V}_{\mathrm{SS}}+\rho_{\mathrm{SF}} \sigma_{\mathrm{S}} \sigma_{\mathrm{F}} \mathrm{SFV}_{\mathrm{SF}}+\frac{1}{2} \sigma_{\mathrm{F}}^{2} \mathrm{~F}^{2} \mathrm{~V}_{\mathrm{FF}} \\
& +\delta_{\mathrm{S}} \mathrm{SV}_{\mathrm{S}}+\delta_{\mathrm{F}} \mathrm{FV}_{\mathrm{F}}+\left(\frac{\mathrm{G}_{\mathrm{S}^{*}}}{\mathrm{t}} \ln \frac{\mathrm{S}^{*}}{\mathrm{G}_{\mathrm{S}^{*}}}\right) \mathrm{V}_{\mathrm{G}_{\mathrm{S}^{*}}}-\mathrm{rV}=0
\end{aligned}
$$

and $\delta_{\mathrm{S}}=\mathrm{r}_{\mathrm{f}}-\mathrm{q}-\rho_{\mathrm{SF}} \sigma_{\mathrm{S}} \sigma_{\mathrm{F}}, \delta_{\mathrm{F}}=\mathrm{r}-\mathrm{r}_{\mathrm{f}}$.

Noting that

$$
\mathrm{X}_{\mathrm{t}}=\left(\mathrm{FS}-\alpha \mathrm{G}_{\mathrm{S}^{*}}\right)^{+}, \mathrm{Y}_{\mathrm{t}}=\left(\mathrm{FS}-\alpha \mathrm{G}_{\mathrm{S}^{*}}\right)^{+}+\delta \mathrm{S}^{*} .
$$

\section{Optimal Exercise Strategy}

Define $\emptyset=\alpha \mathrm{G}_{\mathrm{S}^{*}} / \mathrm{FS}$. Noting the QAG option price $\widetilde{\mathrm{V}}(\varnothing, \mathrm{t})$, we have $\widetilde{\mathrm{V}}=\mathrm{V} / \mathrm{SF}$, and $\widetilde{\mathrm{X}}=(1-\emptyset)^{+}, \widetilde{\mathrm{Y}}=$ $(1-\emptyset)^{+}+\delta$. Hence the region of the QAG option price is

$$
(1-\emptyset)^{+} \leq \widetilde{\mathrm{V}}(\varnothing, \mathrm{t}) \leq \min \left\{(1-\emptyset)^{+}+\delta, \widetilde{\mathrm{V}}^{\mathrm{A}}(\varnothing, \mathrm{t})\right\},
$$

where $\widetilde{\mathrm{V}}^{\mathrm{A}}(\varnothing, \mathrm{t})$ represent corresponding American option.

Lemma 1 Suppose $\delta^{*}=\tilde{V}^{A}(1,0)$. When $\delta \geq \delta^{*}$ the writer should not exercise the option early. Consequently, the option is worth the same as the corresponding American option.

Proof: By the nature of American options, we know that the corresponding American option price $\widetilde{\mathrm{V}}^{\mathrm{A}}(\varnothing, \mathrm{t})$ is monotonically decreasing on $\mathrm{t}$ and $\emptyset$, further $\emptyset_{0} \leq 1$ due to the non-negative payoff of the option holder at the optimal exercise boundary $\emptyset_{0}$.

$\mathrm{FS}<\alpha \mathrm{G}_{\mathrm{S}^{*}}$, namely $\emptyset>1$.

We know that the price of an American option varies depending on the underline asset price. For two American options, the difference between their option values is bounded by the maximal deviation between the two exercise processes (Shreve 2004). In addition, because the game option gives the writer the early callable right, its price should be less than the corresponding American option price. That is,

$$
\widetilde{\mathrm{V}}(\emptyset, \mathrm{t}) \leq \widetilde{\mathrm{V}}^{\mathrm{A}}(\emptyset, \mathrm{t}) \leq \widetilde{\mathrm{V}}^{\mathrm{A}}(\varnothing, 0)<\widetilde{\mathrm{V}}^{\mathrm{A}}(1,0)+(1-\emptyset)^{+} \leq \delta+(1-\emptyset)^{+},
$$

therefore

$$
\widetilde{\mathrm{V}}(\varnothing, \mathrm{t}) \leq \delta+(1-\emptyset)^{+}
$$

$F S>\alpha G_{S^{*}}$ and $F S \in\left(\alpha G_{S^{*}}, S_{0}^{*}\right)$, namely $0<\emptyset<1$, where $S_{0}$ denote the corresponding option optimal exercise boundary.

Due to the option price $\widetilde{V}(\varnothing, t)$ is convexity and monotonically decreasing on $t$, and further consider the

$$
\widetilde{V}(\emptyset, \mathrm{t})-(1-\emptyset)^{+} \leq \widetilde{\mathrm{V}}^{\mathrm{A}}(\emptyset, \mathrm{t})-(1-\emptyset)^{+}<\widetilde{\mathrm{V}}^{\mathrm{A}}(1, \mathrm{t})<\widetilde{\mathrm{V}}^{\mathrm{A}}(1,0) \leq \delta .
$$

Based on the conclusion in (1) and (2), we know that the corresponding American option price $\widetilde{\mathrm{V}}^{\mathrm{A}}(\varnothing, \mathrm{t})$ satisfies the following condition

$$
\widetilde{\mathrm{V}}^{\mathrm{A}}(\emptyset, \mathrm{t}) \leq \delta+(1-\emptyset)^{+}
$$

implying that the writer should not cancel the contract. Hence, the QAG option is worth the same as the corresponding
Bonding conditions

$$
\left(\frac{\partial \widetilde{\mathrm{V}}^{\mathrm{A}}(\varnothing, \mathrm{t})}{\partial \emptyset}\right)_{\emptyset=\emptyset_{0}}=-1 \text { at } \emptyset=\emptyset_{0} .
$$

Then we know that $\widetilde{\mathrm{V}}^{\mathrm{A}}(\emptyset, \mathrm{t})-(1-\emptyset)^{+}$is monotonically increasing on $\varnothing$ when $\varnothing \in\left(\emptyset_{0}, 1\right)$. That is
American option. \#

Lemma 2 Let $\delta=\tilde{V}^{A}\left(1, t^{*}\right)$, and $\tilde{V}^{A}(1, T)<\delta<$ $\tilde{V}^{A}(1,0)$. Then, when $t \geq t^{*}$ the writer should not exercise the option. Namely, only $t \in\left[0, t^{*}\right)$ the writer can exercise the option early.

Proof: Following the arguments in lemma 1, we know $\delta<\widetilde{\mathrm{V}}^{\mathrm{A}}(1,0)$. Considering the corresponding American option price $\widetilde{V}(\varnothing, t)$ is monotonically decreasing on $t$ and 
$\widetilde{\mathrm{V}}(\varnothing, \mathrm{T})=(1-\emptyset)^{+}$, then we have $\delta<0$ if $\delta<\widetilde{\mathrm{V}}^{\mathrm{A}}(1, \mathrm{~T})$. When the option is near expiration, there have In this case, the QAG option is invalid in the market transactions.

$$
\widetilde{\mathrm{V}}(\varnothing, \mathrm{t})-(1-\emptyset)^{+} \leq \widetilde{\mathrm{V}}^{\mathrm{A}}(\varnothing, \mathrm{t})-(1-\emptyset)^{+}<\widetilde{\mathrm{V}}^{\mathrm{A}}(1, \mathrm{t})<\widetilde{\mathrm{V}}^{\mathrm{A}}\left(1, \mathrm{t}^{*}\right)=\delta .
$$

Hence in the case the writer should not exercise the option early. \#

Lemma 3 As soon as asset price process $\emptyset_{t}$ first hits the strike price 1 (that is $F S=\alpha G_{S^{*}}$ ), the writer cancels the contract with optimal stopping strategy that

$$
\hat{t}=\inf \left\{t \geq 0, \emptyset_{t}=1\right\}
$$

Proof: In the case, there have the optimal recall time for the QAG option writer. The optimal recall time for the writer correspond to the time that option holders obtains the smallest payoff. The proof proceeds along the similar lines as the proof of lemma 1.

FS $<\alpha \mathrm{G}_{\mathrm{S}^{*}}$, namely $\emptyset>1$.

In the case, the option is out of the money. The writer will lose the time value of the penalty $\delta S^{*}$ if the writer chose to recall the option early. Hence it would not make sense for the writer to exercise early at all.

FS $>\alpha \mathrm{G}_{\mathrm{S}^{*}}$ and $\mathrm{FS} \in\left(\alpha \mathrm{G}_{\mathrm{S}^{*}}, \mathrm{~S}_{0}^{*}\right)$, namely $0<\emptyset<1$.

In contrast to (1), in the case the option is in the money. The writer will pay an additional $(1-\emptyset)$ if the writer chose to recall the option early in this time. Based on minimizing the total payment, the writer should not recall the option at this time.

To sum up, the QAG option writer have the optimal stopping strategy $\hat{\mathrm{t}}=\inf \left\{\mathrm{t} \geq 0, \emptyset_{\mathrm{t}}=1\right\}$, that is $\mathrm{FS}=\alpha \mathrm{G}_{\mathrm{S}^{*}}$.

$$
\mathrm{LV}\left(\mathrm{S}^{*}, \mathrm{G}_{\mathrm{S}^{*}}, \mathrm{t}\right)=\mathrm{V}_{\mathrm{t}}+\frac{\mathrm{G}_{\mathrm{S}^{*}}}{\mathrm{t}} \ln \left(\frac{\mathrm{S}^{*}}{\mathrm{G}_{\mathrm{S}^{*}}}\right) \mathrm{V}_{\mathrm{G}_{\mathrm{S}^{*}}}+(\mathrm{r}-\mathrm{q}) \mathrm{S}^{*} \mathrm{~V}_{\mathrm{S}^{*}}+\frac{1}{2} \sigma_{\mathrm{S}^{*}}^{2} \mathrm{~S}^{* 2} \mathrm{~V}_{\mathrm{S}^{*} \mathrm{~S}^{*}}-\mathrm{rV}=0 .
$$

(ii) $\mathrm{S}^{*}=\alpha \mathrm{G}_{\mathrm{S}^{*}}$.

In the case, the writer should cancel the option contract, and the option price is equal to $\delta S^{*}$. The price equation can be written by

$$
\mathrm{LV}\left(\mathrm{S}^{*}, \mathrm{G}_{\mathrm{S}^{*}}, \mathrm{t}\right)=-\mathrm{q} \delta \mathrm{S}^{*}
$$

(iii) $\mathrm{S}^{*} \in\left(\mathrm{S}_{0}^{*},+\infty\right)$.

In the case, according to the feature of American option the holder should exercise the option contract, namely $\mathrm{V}\left(\mathrm{S}^{*}, \mathrm{G}_{\mathrm{S}^{*}}, \mathrm{t}\right)=\left(\mathrm{S}^{*}-\alpha \mathrm{G}_{\mathrm{S}^{*}}\right)^{+}$. Noting that

$$
\mathrm{LV}\left(\mathrm{S}^{*}, \mathrm{G}_{\mathrm{S}^{*}}, \mathrm{t}\right)=-\mathrm{qS} \mathrm{S}^{*}-\alpha \frac{\partial \mathrm{G}_{\mathrm{S}^{*}}}{\partial \mathrm{t}}+\mathrm{r} \mathrm{G}_{\mathrm{S}^{*}}
$$

To sum up, the QAG option price satisfies following equation:

$$
\operatorname{LV}\left(\mathrm{S}^{*}, \mathrm{G}_{\mathrm{S}^{*}}, \mathrm{t}\right)=\left\{\begin{array}{cc}
0, & \mathrm{~S}^{*} \in\left(0, \alpha \mathrm{G}_{\mathrm{S}^{*}}\right) \cup\left(\alpha \mathrm{G}_{\mathrm{S}^{*}}, \mathrm{~S}_{0}^{*}\right), \\
-\mathrm{q}^{*} \mathrm{~S}^{*}, & \mathrm{~S}^{*}=\alpha \mathrm{G}_{\mathrm{S}^{*}} \\
-\mathrm{qS}^{*}-\alpha \frac{\partial \mathrm{G}_{\mathrm{S}^{*}}}{\partial \mathrm{t}}+\mathrm{r} \alpha \mathrm{G}_{\mathrm{S}^{*}}, & \mathrm{~S}^{*} \in\left(\mathrm{S}_{0}^{*},+\infty\right) .
\end{array}\right.
$$

By solving the above pricing model, we will get the QAG option pricing formula.

Theorem the quanto Asian game option where the strike price is denominated in domestic currency price is given by

$$
\begin{gathered}
\delta>\tilde{V}^{A}(1,0) \\
V\left(\mathrm{~S}, F, G_{S^{*}}, t\right)=V^{A}\left(S^{*}, G_{S^{*}}, t\right), 0 \leq t \leq T . \\
\delta=\tilde{V}^{A}\left(\emptyset, t^{*}\right), S^{*}(T)=\alpha G_{S^{*}}
\end{gathered}
$$




$$
\begin{gathered}
V\left(\mathrm{~S}, F, G_{S^{*}}, t\right)=V^{A}\left(S^{*}, G_{S^{*}}, t\right), 0 \leq t \leq T . \\
\delta=\tilde{V}^{A}\left(\varnothing, t^{*}\right), S^{*}(T)=\frac{\alpha G_{S^{*}} r}{q} \\
V\left(\mathrm{~S}, F, G_{S^{*}}, t\right)=\left\{\begin{array}{cc}
V^{E}\left(S^{*}, G_{S^{*}}, t\right)+V^{e}\left(S^{*}, G_{S^{*}}, t\right)-V^{D}\left(S^{*}, G_{S^{*}}, t\right), & 0 \leq t<t^{*}, \\
V^{A}\left(S^{*}, G_{S^{*}}, t\right), & t^{*} \leq t \leq T .
\end{array}\right.
\end{gathered}
$$

Where

$$
\begin{aligned}
& V^{A}\left(S^{*}, G_{S^{*}}, t\right)=V^{E}\left(S^{*}, G_{S^{*}}, t\right)+V^{e}\left(S^{*}, G_{S^{*}}, t\right), \\
& V^{E}\left(S^{*}, G_{S^{*}}, t\right)=S^{*} e^{\left(\delta_{S^{*}-\mathrm{r}}\right)(T-t)}\left[N\left(d_{1}\right)-\alpha\left(\frac{G_{S^{*}}}{S^{*}}\right)^{\frac{t}{T}} e^{-Q} N\left(d_{2}\right)\right], \\
& V^{D}\left(S^{*}, G_{S^{*}}, t\right)=\delta S^{*}\left[\left(\frac{\alpha G_{S^{*}}}{S^{*}}\right)^{\frac{\left(\mu_{S^{*}}-\sqrt{2 \sigma_{S^{*}}^{2} *+\mu_{S^{*}}^{2}}\right) y}{\sigma_{S^{*}}^{2}}} N\left(f_{2}\right)+\left(\frac{\alpha G_{S^{*}}}{S^{*}}\right) \frac{\left(\mu_{S^{*}} \sqrt{2 \sigma_{S^{*}}^{2}+\mu_{S^{*}}^{2}}\right) y}{\sigma_{S^{*}}^{2}} N\left(h_{2}\right)\right] \text {, }
\end{aligned}
$$

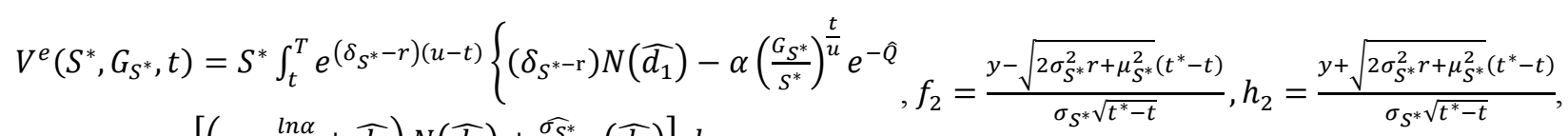

$$
\begin{aligned}
& {\left[\left(r-\frac{\ln \alpha}{u}+\widehat{d_{3}}\right) N\left(\widehat{d_{2}}\right)+\frac{\widehat{\sigma_{S^{*}}}}{u^{2}} n\left(\widehat{d_{2}}\right)\right] d u} \\
& \delta_{S^{*}}=r-q, \mu_{S^{*}}=\delta_{S^{*}}+\frac{1}{2} \sigma_{S^{*}}^{2}, y=\operatorname{tln} \frac{\alpha G_{S^{*}}}{S^{*}}, \\
& d_{1}=\left[\operatorname{tln}\left(\frac{S^{*}}{\alpha G_{S^{*}}}\right)-(T-t) \ln \alpha+\frac{1}{2} \mu_{S^{*}}\left(T^{2}-t^{2}\right)\right] /\left(\sigma_{S^{*}} \sqrt{\left(T^{3}-t^{3}\right) / 3}\right) \text {, } \\
& d_{2}=d_{1}-\frac{\sigma_{S^{*}}}{T}, Q=\frac{\mu_{S^{*}}}{2}\left(\frac{T^{2}-t^{2}}{T}\right)-\frac{\sigma_{S^{*}}^{2}}{6}\left(\frac{T^{3}-t^{3}}{T^{2}}\right), \\
& \widehat{d_{1}}=\frac{u \ln \frac{\alpha G_{S^{*}}}{S_{0}^{*}}-\operatorname{tln} \frac{\alpha G_{S^{*}}}{S^{*}}+\frac{\mu_{S^{*}}}{2}\left(u^{2}-t^{2}\right)}{\widehat{\sigma}}, \widehat{d_{2}}=\widehat{d_{1}}-\frac{\widehat{\sigma}}{u}, \widehat{\sigma}^{2}=\frac{\sigma_{S^{*}}^{2}\left(u^{3}-t^{3}\right)}{3}, \\
& \widehat{d_{3}}=\frac{\operatorname{tln} \frac{G_{S^{*}}}{S^{*}}+u \ln \alpha-\frac{\mu_{S^{*}}}{2}\left(u^{2}-t^{2}\right)+\frac{\widehat{\sigma}^{2}}{u}}{u^{2}}, \hat{Q}=\frac{\hat{\sigma}}{2 u^{2}}-\frac{\mu_{S^{*}}}{2 u}\left(u^{3}-t^{3}\right) .
\end{aligned}
$$

$\mathrm{N}(\cdot)$ and $\mathrm{n}(\cdot)$ denote cumulative normal distribution function and the standard normal distribution function respectively.

\section{Conclusion}

In this paper, we studied the pricing behaviors of the quanto Asian game option where the strike price is denominated in domestic currency and the strike price follows the geometric average distribution and obtaining the integral expression of pricing formula under the finite horizon case. Furthermore, we discussed optimal exercise strategies and continuation regions of options. As a consequence, the quanto Asian game option can be analyzed as a mixture of two exotic options, i.e., American and European quanto Asian barrier options. The game options with callable features are more flexible than American options. After the issuance of an option, the writer is no longer a passive player; he may terminate the contract to safeguard his own interest before the expiration of the option.
The game options with callable features are also cheaper than the American-style options and thus are more conducive to the writer.

\section{References}

[1] Kifer, Y. Game options [J]. Finance and Stochastic, 2000, 4: 443-463.

[2] Kwok, Y. K., L. X. Wu. Effects of Callable Feature on Early Exercise Policy [J]. Review of Derivatives Research, 2000, 4: 189-211.

[3] Dai, M. A Closed Form Solution to Perpetual American Floating Strike Lookback Option [J]. Journal of Computational Finance, 2001, 4: 63-68.

[4] Kyprianou, A. E. Some Calculations for Israeli Options [J]. Finance and Stochastics, 2004, 8: 73-86.

[5] Baurdoux E J, Kyprianou A E. Further calculations for Israeli options [J]. Stochastics and Sto-chastics Reports, 2004, 76 (6): 549-569. 
[6] Hernandez U, Luis G. Pricing of Game Options in a market with stochastic interest rates [D]. America: School of mathematics of Georgia institute of technology, 2005.

[7] Ekström, E. (2006). Properties of game options. Mathematical Methods of Operations Research, 63, 221-238.

[8] Kuhn, C. and A. E. Kyprianou. Callable as Composite Exotic Options [J]. Mathematical Finance, 2007, 17: 487-502.

[9] Dolinsky Y, Kifer Y. Hedging with risk for game options in discrete time $[\mathrm{J}]$. Stochastics An International Journal of Probability and Stochastic Processes, 2007, 79 (1-2): 169-195.

[10] Peidong Guo, Qihong Chen, Xicai Guo, Yue Fang. Path-dependent game options: a lookback case [J] Rev Deriv Res, 2014, 17: 113-124.

[11] Yam S C P, Yung S P, Zhou W. Game call options revisited [J]. Mathematical Finance, 2014, 24 (1): 173-206.

[12] Park K, Jeon J. A simple and fast method for valuing American knock-out options with rebates [J]. Chaos Solitons Fractals, 2017, 103: 364-70.

[13] Le N, Dang D. Pricing American-style Parisian down-and-out call options [J]. Appl Math Comput, 2017, 305: 330-47.

[14] Balajewicz M, Toivanen J. Reduced order models for pricing European and American options under stochastic volatility and jump-diffusion models [J]. J Comput Sci, 2017, 20: 198-204.

[15] Gong X, Zhuang X. American option valuation under time changed tempered stable Lévy processes [J]. Phys. A, 2017, 466: 57-68.

[16] Kang M, Jeon J, Han H, Lee S. Analytic solution for American strangle options using Laplace-Carson transforms [J]. Commun Nonlinear Sci NumerSimul, 2017, 47: 292-307.

[17] Zhao H, Yang H. Semismooth Newton methods with domain decomposition for American options [J]. Journal of Computational and Applied Mathematics, 2018, 337: 37-50.

[18] Chen W, Du K, Qiu X. Analytic properties of American option prices under a modified Black-Scholes equation with spatial fractional derivatives [J]. Phys A, 2018; 491: 37-44.

[19] Madi S, Bouras M, Haiour M, Stahel A. Pricing of American options, using the Brennan-Schwartz algorithm based on finite elements [J]. Applied Mathe-matics and Computation, 2018, 339: 846-52.

[20] Soleymani F, Barfeie M, Haghani F. Inverse multi-quadric RBF for computing the weights of FD method: application to American options [J]. Commun Nonlinear Sci NumerSimul, 2018, 64: 74-88.

[21] Chen C, Wang Z, Yang Y. A new operator splitting method for American options under fractional Black-Scholes models [J]. Computers \& Mathematics with Applications, 2019, 77 (8): $2130-44$.

[22] Zaevski T. A new form of the early exercise premium for American type derivatives [J]. Chaos Solitons Fractals, 2019, 123: $338-40$.

[23] Gao Y, Song H, Wang X, Zhang K. Primal-dual active set method for pricing American better-of option on two assets [J]. Communications in Nonlinear Science and Numerical Simulation, 2020, 80: 104976.

[24] Tsvetelin S. Zaevski. Discounted perpetual game call options [J]. Chaos Solitons Fractals, 2020, 131: 109503. 